\title{
PRA $A^{*}$-MODUL ATAS PRA $A^{*}$-ALJABAR DAN ALJABAR IF-THEN-ELSE ATAS PRA $A^{*}$-ALJABAR
}

\author{
KHAINDRA \\ Program Studi Matematika, \\ Fakultas Matematika dan Ilmu Pengetahuan Alam, Universitas Andalas, \\ Kampus UNAND Limau Manis Padang, Indonesia. \\ andrak79@yahoo.com
}

\begin{abstract}
Abstrak. Tulisan ini mengkaji operasi if-then-else yang membahas Pra $A^{*}$-Modul atas Pra $A^{*}$-Aljabar dan aljabar if-then-else atas Pra $A^{*}$-Aljabar. Dinotasikan koleksi dari aljabar if-then-else atas $A$ sebagai A-ITE dan koleksi dari Pra $A^{*}$-Modul sebagai AMOD.
\end{abstract}

Kata Kunci: Aljabar Boolean, Operasi if-then-else, Aljabar if-then-else atas Pra $A^{*}$ Aljabar, Pra $A^{*}$-Modul atas Pra $A^{*}$-Aljabar

\section{Pendahuluan}

E.G. Manes [2] memperkenalkan teori persamaan dari operasi if-then-else dari bahasa pemograman dalam bentuk:

$$
\text { if } f_{p}(f, g)(x)=\left\{\begin{array}{l}
f(x), \text { if } p(x) \text { adalah benar } \\
g(x), \text { if } p(x) \text { adalah salah }
\end{array}\right.
$$

E.G. Manes [2] telah mengkaji aljabar if-then-else atas aljabar Boolean, ADAs, aljabar C dan juga mempelajari modul atas aljabar Boolean, ADAs, aljabar C serta membuktikan ekivalen antara aljabar if-then-else atas aljabar dan modul atas aljabar yang bersesuaian.

Dalam tulisan ini akan diperkenalkan aljabar if-then-else atas Pra $A^{*}$-Aljabar dan Pra $A^{*}$-modul atas Pra $A^{*}$-Aljabar serta mempelajari sifat sifatnya yang merupakan kajian daripenulisan.

Definisi 1.1. [5] Misalkan A adalah suatu himpunan tak kosong. Suatu sistem matematika $\left(A, \wedge, \vee,(-)^{\sim}\right)$ dikatakan suatu Pra $A^{*}$-Aljabar dan dinotasikan dengan $\bar{A}$ dan $\wedge, \vee$ suatu operasi biner $(-)^{\sim}$ operasi unary, jika untuk setiap $x, y, z \in A$ berlaku:

(1) $x^{\sim \sim}=x$.

(2) $x \wedge x=x$.

(3) $x \wedge y=y \wedge x$

(4) $(x \wedge y)^{\sim}=x^{\sim} \vee y^{\sim}$.

(5) $x \wedge(y \wedge z)=(x \wedge y) \wedge z$.

(6) $x \wedge(y \vee z)=(x \wedge y) \vee(x \wedge z)$. 
(7) $x \wedge y=x \wedge\left(x^{\sim} \vee y\right)$.

Suatu Pra $A^{*}$-Aljabar $\bar{A}$ dikatakan mempunyai identitas untuk $\wedge$ jika terdapat suatu $a \in A$ sedemikian sehingga $a \wedge x=x \wedge a=x, \forall x \in A$. Jika Pra $A^{*}$-Aljabar $\bar{A}$ mempunyai identitas untuk $\wedge$, maka identitasnya adalah tunggal dan dinotasikan dengan 1. Suatu Pra $A^{*}$-Aljabar $\bar{A}$ dikatakan mempunyai identitas untuk $\vee$ jika terdapat suatu $a \in A$ sedemikian sehingga $a \vee x=x \vee a=x, \forall x \in A$. Jika Pra $A^{*}$-Aljabar $\bar{A}$ mempunyai identitas untuk $\vee$, maka identitasnya adalah tunggal dan dinotasikan dengan 0 .

Contoh 1.2. Misalkan himpunan $\mathbf{W}=\{0,1,2\}$ adalah suatu Pra $A^{*}$-Aljabar dengan operasi $\wedge, \vee,(\cdot) \sim$ yang didefinisikan seperti pada Tabel 1 untuk operasi $\wedge$, Tabel 2 untuk operasi $\vee$ dan Tabel 3 untuk operasi $\sim$ :

Tabel 1. Operasi $\wedge$ pada $\bar{A}$

\begin{tabular}{|l|l|l|l|}
\hline$\wedge$ & 0 & 1 & 2 \\
\hline 0 & 0 & 0 & 2 \\
\hline 1 & 0 & 1 & 2 \\
\hline 2 & 2 & 2 & 2 \\
\hline
\end{tabular}

Tabel 2. Operasi biner $\vee$ pada $\bar{A}$

\begin{tabular}{|c|c|c|c|}
\hline$\vee$ & 0 & 1 & 2 \\
\hline 0 & 0 & 1 & 2 \\
\hline 1 & 1 & 1 & 2 \\
\hline 2 & 2 & 2 & 2 \\
\hline
\end{tabular}

Tabel 3. Operasi $\sim$ pada $\bar{A}$

\begin{tabular}{|c|c|}
\hline $\mathrm{x}$ & $x^{\sim}$ \\
\hline 0 & 1 \\
\hline 1 & 0 \\
\hline 2 & 2 \\
\hline
\end{tabular}

Dari contoh tersebut diperoleh:

(1) $2^{\sim}=2$,

(2) $1 \wedge x=x$ untuk semua $x \in W$,

(3) $0 \vee x=x$ untuk semua $x \in W$,

(4) $2 \wedge x=2 \vee x=2$. 


\section{Operasi If-Then-Else}

Definisi 2.1. [5] Misalkan $\bar{A}$ merupakan sebuah Pra $A^{*}$-Aljabar yang memuat 1 . Misalkan $x, p, q \in A$. Operasi if-then-else atas $\bar{A}$ didefinisikan sebagai:

$$
i f_{x}(p, q):=(x \wedge p) \vee\left(x^{\sim} \wedge q\right) .
$$

Proposisi 2.2. [5] Setiap Pra $A^{*}$-Aljabar dengan beberapa konstanta tertentu harus memenuhi hukum berikut:

(i) $i f_{2}(p, q)=2$,

(ii) $i f_{x}(2,2)=2$,

(iii) $i f_{1}(p, q)=p(q \neq 2)$,

(iv) $i f_{0}(p, q)=q(p \neq 2)$,

(v) $i f_{x}(1,0)=x$.

\section{Bukti.}

(i) Akan dibuktikan $i f_{2}(p, q)=2$.

Perhatikan bahwa

$$
\begin{aligned}
i f_{2}(p, q) & =(2 \wedge p) \vee\left(2^{\sim} \wedge q\right), \\
& =2 \vee(2 \wedge q), \\
& =2 \vee 2 \\
& =2
\end{aligned}
$$

(ii) Akan dibuktikan $i f_{x}(2,2)=2$.

Perhatikan bahwa

$$
\begin{aligned}
i f_{x}(2,2) & =(x \wedge 2) \vee\left(x^{\sim} \wedge 2\right) \\
& =2 \vee 2 \\
& =2
\end{aligned}
$$

Pembuktian (iii) - (v) dilakukan dengan cara yang sama.

Proposisi 2.3. [5] Setiap Pra $A^{*}$-Aljabar memiliki aturan sebagai berikut:

(i) $i f_{x \sim} \sim(p, q)=i f_{x}(q, p)$.

(ii) $i f_{x}(p, q) \wedge r=i f_{x}(p \wedge r, q \wedge r)$.

(iii) $i f_{x}(p, q) \vee r=i f_{x}(p \vee r, q \vee r)$

(iv) $i f_{x}\left(i f_{y}(p, q), i f_{y}(r, s)\right)=i f_{y}\left(i f_{x}(p, r), i f_{x}(q, s)\right)$.

(v) $i f_{x \vee y}(p, q)=i f_{x}\left(p, i f_{y}(p, q)\right)$.

(vi) $i f_{x \wedge y}(p, q)=i f_{x}\left(i f_{y}((p, q), q)\right)$.

(vii) $i f_{p}(p, p)=p$.

\section{Bukti.}


(i) Akan dibuktikan $i f_{x \sim}(p, q)=i f_{x}(q, p)$.

Perhatikan bahwa

$$
\begin{aligned}
i f_{x^{\sim}}(p, q) & =\left(x^{\sim} \wedge p\right) \vee\left(x^{\sim \sim} \wedge q\right), \\
& =\left(x^{\sim} \wedge p\right) \vee(x \wedge q), \\
& =(x \wedge q) \vee\left(x^{\sim} \wedge p\right), \\
& =i f_{x}(q, p) .
\end{aligned}
$$

(ii) Akan dibuktikan $i f_{x}(p, q) \wedge r=i f_{x}(p \wedge r, q \wedge r)$.

Perhatikan bahwa

$$
\begin{aligned}
i f_{x}(p, q) \wedge r & =\left((x \wedge p) \vee\left(x^{\sim} \wedge q\right)\right) \wedge r, \\
& =\{(x \wedge p) \wedge r\} \vee\left\{\left(x^{\sim} \wedge q\right) \wedge r\right\}, \\
& =\{x \wedge(p \wedge r)\} \vee\left\{x^{\sim} \wedge(q \wedge r)\right\}, \\
& =i f_{x}(p \wedge r, q \wedge r) .
\end{aligned}
$$

Pembuktian (iii) - (vii) dilakukan dengan cara yang sama.

Proposisi 2.4. [5] Misalkan $A$ adalah Pra $A^{*}$-Aljabar, $a \in B(A)$, maka if $_{a}(p, p)=$ $p, \forall p \in A$.

\section{Pra $A^{*}$-modul atas Pra $A^{*}$-Aljabar dan Aljabar If-then -else atas Pra $A^{*}$-Aljabar}

Dalam bagian ini akan dijelaskan Pra $A^{*}$-modul atas Pra $A^{*}$-Aljabar dan aljabar if-then-else atas Pra $A^{*}$-Aljabar. Selanjutnya akan dikaji koleksi A-ITE dari semua aljabar if-then-else atas $A$ dan variasi $A$-Mod dari Pra $A^{*}$-modul atas $A$.

Definisi 3.1. [5] Misalkan $\left(A, \wedge, \vee,(-)^{\sim}, 0,1,2\right)$ adalah Pra $A^{*}$-Aljabar. Suatu aljabar if-then-else atas $A$ adalah aljabar $\left(X, \cup, \varphi, \mathrm{if}_{p}(-,-)\right)$ dimana $X$ adalah himpunan tak kosong, $\cup$ adalah operasi biner, $\varphi$ adalah elemen identitas dan if $_{p}(-,-)$ adalah operasi if-then-else, $p \in A$. Untuk semua $f, g, h \in X$ dan $p, q, r \in A$ berlaku:

(i) $f \cup(g \cup h)=(f \cup g) \cup h$.

(ii) $f \cup g=g \cup f$.

(iii) $f \cup \varphi=f, f \cup f=f$.

(iv) $i f_{1}(f, g)=f, i f_{0}(f, g)=g, i f_{2}(f, g)=\varphi$.

(v) $i f_{p}(f \cup a, g \cup b)=i f_{p}(f, g) \cup i f_{p}(a, b)$.

Selanjutnya didefinisikan $i f_{p q r}(f, g)=i f_{p}\left(i f_{q}(f, g), i f_{r}(f, g)\right)$. Kemudian dinotasikan koleksi dari aljabar if-then-else atas A adalah A-ITE.

Definisi 3.2. [5] Misalkan A adalah suatu Pra $A^{*}$-Aljabar dengan 0,1,2. Suatu Pra $A^{*}$-modul atas $A$ adalah semi-lattice $(X, \cup, \varphi)$ dengan $\cup$ biner, $\varphi$ identitas, dan suatu operasi unary $f$ yakni $p f$, untuk semua $f \in X, p \in A$ yang memenuhi:

(i) $p(f \cup g)=p f \cup p g$.

(ii) $0 f=\varphi=p \varphi$. 
(iii) $1 f=f ; 2 f=\varphi$,

dan selanjutnya didefinisikan $(p q r) f=p(q f) \cup p^{\sim}(r f)$. Kemudian dinotasikan koleksi dari Pra $A^{*}$-modul adalah A-Mod.

Teorema 3.3. [5] A-ITE dan A-Mod adalah koleksi yang ekivalen. Struktur A-Mod dari aljabar if-then-else diberikan sebagai $p f=i f_{p}(f, \varphi)$ dimana suatu bagian invers adalah $i f_{p}(f, g)=p f \cup p^{\sim} g$.

Bukti. Misalkan $\left(X, \cup, \varphi, i f_{p}(-,-)\right)(p \in A)$ adalah suatu aljabar if-then-else. Jelas $(X, \cup, \varphi)$ adalah suatu semi-lattice dengan identitas $\varphi$. Sekarang didefinisikan untuk $p \in A, f \in X, p f=i f_{p}(f, \varphi)$ :

(i) Akan dibuktikan $(p q r) f=p(q f) \cup p^{\sim}(r f)$.

Perhatikan bahwa

$$
\begin{aligned}
(p q r) f & =i f_{p q r}(f, \varphi), \\
& =i f_{p}\left(i f_{q}(f \cdot \varphi), i f_{r}(f, \varphi)\right),(\text { Definisi 3.2), } \\
& =i f_{p}(q f, r f), \\
& =p(q f) \cup p^{\sim}(r f) .
\end{aligned}
$$

(ii) Akan dibuktikan $p(f \cup g)=p f \cup p g$.

Perhatikan bahwa

$$
\begin{aligned}
p(f \cup g) & =i f_{p}(f \cup g, \varphi), \\
& =i f_{p}(f \cup g, \varphi \cup \varphi)(\text { Definisi 3.2) } \\
& =i f_{p}(f, \varphi) \cup i f_{p}(g, \varphi) \text { (Definisi 3.2) } \\
& =p f \cup p g .
\end{aligned}
$$

(iii) Akan dibuktikan $0 f=\varphi$.

Perhatikan bahwa

$$
\begin{aligned}
0 f & =i f_{0}(f, \varphi), \\
& =\varphi(\text { Definisi 3.2). }
\end{aligned}
$$

(iv) Akan dibuktikan

(1) $1 f=f$.

Perhatikan bahwa

$$
\begin{aligned}
1 f & =i f_{1}(f, \varphi) \\
& =f(\text { Definisi 3.2). }
\end{aligned}
$$

(2) $2 f=\varphi$.

Perhatikan bahwa

$$
\begin{aligned}
2 f & =i f_{2}(f, \varphi) \\
& =\varphi(\text { Definisi 3.2). }
\end{aligned}
$$

Oleh karena itu terbukti $(X, \cup, \varphi)$ adalah suatu Pra $A^{*}$-modul atas $A$. 
Sebaliknya misalkan $(X, \cup, \varphi)$ adalah suatu Pra $A^{*}$-modul atas $A$.

Dengan jelas $(X, \cup, \varphi)$ memenuhi 3.1 (i),(ii) dan (iii). Didefinisikan, $\forall p \in A$ dan untuk semua $f, g \in X$ oleh $i f_{p}(f, g)=p f \cup p^{\sim} g$.

(i) Akan dibuktikan $i f_{p q r}(f, g)=i f_{p}\left(i f_{q}(f, g) \cdot i f_{r}(f, g)\right)$.

Perhatikan bahwa

$$
\begin{aligned}
i f_{p q r}(f, g) & =(p q r) f \cup(p q r)^{\sim} g, \\
& =(p q r) f \cup\left(p q^{\sim} r^{\sim}\right) g, \\
& =p(q f) \cup p^{\sim}(r f) \cup p\left(q^{\sim} g\right) \cup p^{\sim}\left(r^{\sim} g\right), \\
& =p\left(q f \cup q^{\sim} g\right) \cup p^{\sim}\left(r f \cup r^{\sim} g\right), \\
& =p\left(i f_{q}(f, g)\right) \cup p^{\sim}\left(i f_{r}(f, g)\right), \\
& =i f_{p}\left(i f_{q}(f, g) . i f_{r}(f, g)\right) .
\end{aligned}
$$

(ii) Akan dibuktikan

(1) if $(f, g)=1$.

Perhatikan bahwa

$$
\begin{aligned}
i f_{1}(f, g) & =1 . f \cup 1^{\sim} g, \\
& =f \cup(0 . g)(\text { Definisi 3.2), } \\
& =f \cup \varphi(\text { Definisi 3.2), } \\
& =f(\text { Definisi 3.2). }
\end{aligned}
$$

(2) $i f_{0}(f, g)=g$.

Perhatikan bahwa

$$
\begin{aligned}
i f_{0}(f, g) & =0 . f \cup 0^{\sim} g, \\
& =\varphi \cup 1 g(\text { Definisi 3.2), } \\
& =\varphi \cup g(\text { Definisi 3.2), } \\
& =g(\text { Definisi 3.2). }
\end{aligned}
$$

(3) $i f_{2}(f, g)=\varphi$.

Perhatikan bahwa

$$
\begin{aligned}
i f_{2}(f, g) & =2 . f \cup 2^{\sim} g, \\
& =\varphi \cup \varphi(\text { Definisi 3.2), } \\
& =\varphi(\text { Definisi 3.2). }
\end{aligned}
$$

(iii) Akan dibuktikan $i f_{p}(f \cup a, g \cup b)=i f_{p}(f, g) \cup i f_{p}(a, b)$.

Perhatikan bahwa

$$
\begin{aligned}
i f_{p}(f \cup a, g \cup b) & =p(f \cup a) \cup p^{\sim}(g \cup b), \\
& =p f \cup p a \cup p^{\sim} g \cup p^{\sim} b \text { (Definisi 3.2), } \\
& =p f \cup p^{\sim} g \cup p a \cup p^{\sim} b, \\
& =i f_{p}(f, g) \cup f_{p}(a, b) .
\end{aligned}
$$

Karna itu $\left(X, \cup, \varphi, i f_{p}(-,-)\right)(p \in A)$ adalah aljabar if-then-else atas $A$. Oleh karena itu terbukti bahwa $A$-ITE dan $A$-Mod adalah koleksi yang ekivalen. 


\section{Ucapan Terima kasih}

Penulis mengucapkan terima kasih kepada Ibu Dr. Yanita, Bapak Narwen M.Si, dan Ibu Dr Susila Bahri yang telah memberikan masukan dan saran dalam penyempurnaan penulisan artikel ini.

\section{Daftar Pustaka}

[1] Guzman, F dkk. 1990. The Algebra of Conditional Logic, Algebra Universalis: $88-110$

[2] Manes E.G. 1993. ADAs and the Equational Theory of If-Then-Else, Algebra Universalis, 373 - 394

[3] Birkhoff, G. 1948. Lattice Theory, Revised Edition, America Mathematical Society

[4] Munir, R. Matematika Diskrit, Edisi Ketiga, Penerbit Informatika Bandung

[5] Rao, J.V dkk. 2009. Pre $A^{*}$-Modules and If-Then-Else Algebra Over Pre $A^{*}$ Algebra, International Journal of Systemic, Cybernetics and Informatics: 11 15 